\title{
The Application of the Anchor Rod Retaining Wall in Building Slope
}

\author{
Research \\ Xiao Qiang Wu \\ (yanan university construction engineering school, shaanxi yanan,china, 716000) \\ Email:nwwolf197724@163.com
}

Keywords: Geotechnical; Engineering; The anchor rod retaining wall; The supporting

\begin{abstract}
With the continuous development of China's modernization, the construction of large-scale construction, make the high slope in the construction project of geotechnical engineering projects has increased dramatically. How to solve the contradiction between high slope with complex topography and geology conditions, has become a problem to be solved. This paper introduces the anchor rod retaining wall technology combined with specific engineering example in the construction design and application of high slope. Anchor flexible retaining wall construction, safety, economy, obtained the very good application in the project. Anchor rod retaining wall are widely used in railway, highway engineering, also used in good condition. As a result, the anchor rod retaining wall in high slope protection engineering has a broad application prospect.
\end{abstract}

\section{The introduction}

Anchor rod retaining wall is a new type of combined support technology, it is made of reinforced concrete wall column (rib, panel) and anchor rod retaining wall structure, it relies on anchoring bolt in the stability of rock and soil layer pull-out force balance metope place of earth pressure, the stability of the structure. With the construction of the city, in the engineering construction inevitably appeared some high slope. Especially because of the grading, located in the hillside near the steep terrain, the high places of the roadbed such as without retaining wall, embankment slope up to 10 meters, unable to ensure its safe use as a construction project itself, roadbed stability and security; So should be the slope supporting ${ }^{[1,2,3]}$.

\section{Engineering application examples}

This project is located in yan 'an, beside the project for two residential buildings, and the original retaining wall partly damaged by natural disasters, so the need for reinforcement and maintenance. Originally the address house demolition behind the formation of the slope, height difference more than 20 meters, the terrain is more complex. To make full use of land, protect the original housing project, USES the anchor rod retaining wall retaining wall of the original building slope reinforcement and protection ${ }^{[4,5,6]}$.

\section{The calculation of the structure}

1) the surface according to supported on the frame beam of bidirectional board according
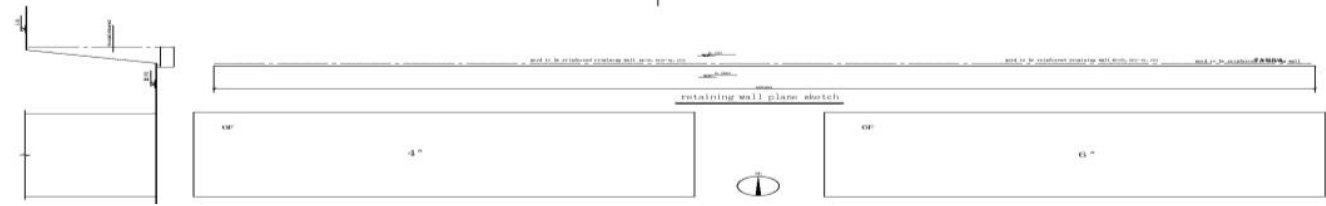

Figure. 1 retaining wall topographic map

to elasticity theory to calculate. On the front panel mainly in permanent load pressure, subentry coefficient 1.2; Live load for the lateral pressure caused by the additional load on the ground, subentry coefficient 1.4; On the front panel triangular distributed load simplified according to the 
principle of fixed end moment is equal to the uniformly distributed load.

2) vertical continuous beam and anchor force level of beam end shear beam with combined. Bolt force was determined, can choose to anchor body muscle and the determination of anchorage length. Bolt force was determined, can choose to anchor body muscle and the determination of anchorage length. Anchor damage consequences for engineering, and public safety problem, according to the design and construction of soil layer anchor (CECS22:90) take the bolt's safety factor $K=2.2$. At the same time, the anchor reinforcement calculation when should be appropriate to consider the influence of the anchor rod body corrosion.

3) checked

The project is located fortification intensity is 6 degrees, at the same time considering horizontal seismic action and vertical seismic action. $\mathrm{KH}=0.1$ horizontal seismic coefficient, vertical seismic coefficient $\mathrm{KH} / 3=1 / 15 \mathrm{KV}=2$. The lateral pressure caused by the earthquake incremental subentry coefficient $1 / 13$. The ground side pressure produced by the additional load combination will not be involved. Aseismic calculation include: surface seismic calculation, the aseismic calculation of aseismic calculation, anchor beam with.

4) the overall stability of stratified excavation by Bishop distribution calculation. Each step excavation shall be calculated overall stability. Each step excavation overall stability safety coefficient is greater than 1.25. Exactly when the integral safety factor of slope excavation is greater than 1.

\section{The anchor rod retaining wall design}

1) anchor construction

Bolt hole to stop digging anchor rod anchor head elevation 0.5 meters, anchoring bolt positioning and drilling operations, using mechanical into a hole, it is forbidden to note slurry-supported. Anchor outside the threaded portion of the secondary steel ( $36 \mathrm{~mm}$ in diameter), processing to finished product in advance after welding on level $3(25 \mathrm{~mm})$ diameter steel anchor, set a position along the length of 1.5 M. Mechanical drilling diameter of $160 \mathrm{~mm}$, tip down $15^{\circ}$ ) with PVC pipe bolt free period (.) grouting pipe fitting anchor tie together, a grouting pipe is $200 \mathrm{~mm}$ from the bottom, the M25 cement mortar (with vegan slurry) is prohibited. Grouting pressure is between 0.5 $\sim 1.0 \mathrm{MPa}$ (3\% of the dosage of cement can be added expansion agent).

2) beam construction

Anchor construction after the completion of a layer, according to the drawings for die casting beams, tensioning bolt in 28 days. After ripping with M10 cement mortar paint $20 \mathrm{~mm}$. Advance in a diameter of 50 MMPVC drain pipe, back fill in the pebbles filter layer. Fill in expansion joints with asphalt mortar.

3) excavation supporting information monitoring

During the period of constructing, the retaining wall for settlement, tilt observation, the retaining wall for horizontal displacement observation. Monitoring items in front of the anchor cable construction of the initial value should not be less than two times. Observations once every morning during excavation, excavation, within one month after two days of observation, then once a week before to backfill. When the horizontal displacement of retaining more than $10 \mathrm{~mm}$ or signs or accident, should be continuous observation, $2 \mathrm{~h}$ reading time, and timely notify the design, supervision and owner, respond as soon as possible. Measurement unit shall have corresponding qualifications, the after submit complete monitoring report.

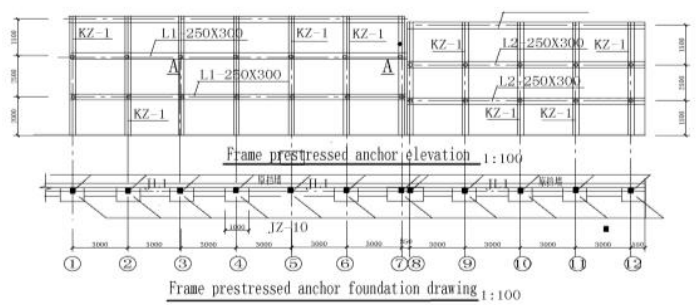

Figure. 2 frame prestressed anchor foundation 


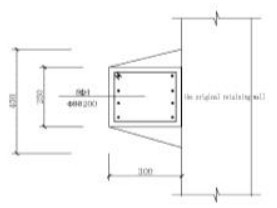

L.2.2transverse section

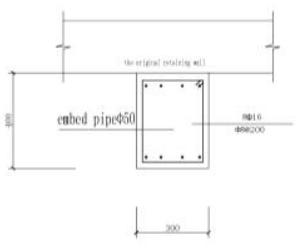

KZ-Itransverse section

Figure. 3 frame beam and frame column section and elevation figure

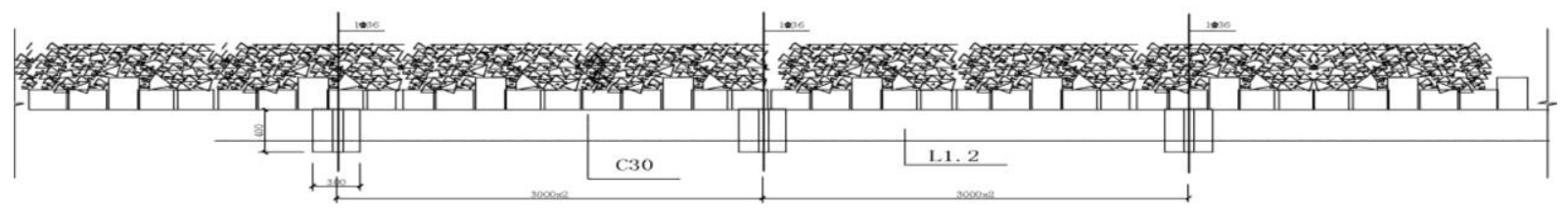

Figure. $\frac{\mathrm{A}-\mathrm{A}}{4 \text { retaining wall section }}$

\section{Set in the rock bolt problems should be paid attention to}

Allow the cohesive force between grout and rock depends on the intact rock compressive strength, the size of the joint and fracture spacing in the rocks, and the influence of bit of rock pin knot, as well as on the surface of the rock hole cleanliness. Large diameter or broad ring space, as a result of mortar contraction weakened cohesive force. If the swelling mortar, can obtain good effect. In anchor rod design, mortar and the cohesive force of the rock are key factors, rather than increase the anchorage length without increasing the diameter of the hole, in order to get the permissible value. Set up the Anchor should pay attention to when shale stratification state, inclined bedding surface cracks and bedding direction, thickness of strata and influence, etc[8 10];

\section{Conclusion}

Through this project design, can wait until the following conclusion:

1) retaining wall slope with anchor rod retaining wall structure, and using the above method is feasible.2) the surface layer and the frame beam adopts pouring concrete is convenient construction and save construction cost.3) permanent slope should consider the influence of seismic.

In short, the anchor rod retaining wall with material province, covers an area of less, construction is convenient wait for a characteristic, bolt on the slope of small disturbance, prestressed anchor rod to control the deformation of structure etc, with the further development of the anchor technology, the anchor rod retaining wall in railway, highway subgrade engineering and architectural engineering will get more extensive application in geotechnical engineering.



Figure. 5 prestressed anchor

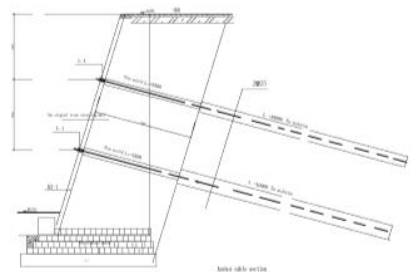

Figure. 6 retaining wall section 


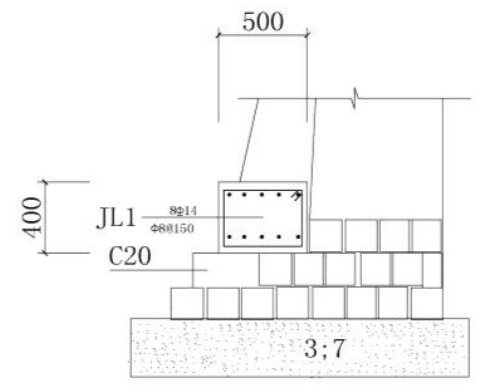

$$
\frac{\text { KZ1 based on detail }}{\text { Sote: } \text { KII vertical reinforcenent inserted vithin }}
$$

Figure. 7 detail of frame column foundation

\section{Reference}

[1]DZ/T 0219-2006, the Landslide Control Project Design and Construction Technical Specification $[\mathrm{S}]$.

[2] GB 50330-50330, the Building Slope Engineering Technical Specifications [S].

[3] W.Y. Zhou. Present Situation and Prospect of Rock Mass Mechanics Numerical Method [J]. Journal of rock mechanics and engineering, 1993, 12 (1) : 84-88.

[4]. The Finite Element Simulation and Stability Analysis of Slope Excavation [J]. Journal of rock mechanics and engineering, 2002, 21 (6) : 843-847.

[5] H,M. Su, Static Pressure Precast Pile Influence on Surrounding Buildings and Countermeasures [J]. Architectural technology development, 2000, 27 (6) : 8-9.

[6] H.R. Zhou, Soil Mechanics and Foundation Engineering [M]. Wuhan: wuhan university of technology press, 1988

[7] Z.X. Li, Method and Its Application in Static Load Pile Test [J]. Architectural technology, 2000, 31 (3) : 157-159.

[8]G.Q. Luo. Masonry Structure [M]. Changsha: hunan science and technology press, 1993.

[9] DZ/T 0219-2006, the Landslide Prevention and Control of Engineering Design and Construction Technical Specification [S].

[10] GB 50330-50330, the Building Slope Engineering Technical Specifications [S]. 